\title{
Parental Concerns in 100th Year Anniversary of Sociology Education in Turkey
}

\author{
Aytul Kasapoglu \\ Department of Sociology, Ankara University, Turkey
}

Copyright (C) 2016 by authors, all rights reserved. Authors agree that this article remains permanently open access under the terms of the Creative Commons Attribution License 4.0 International License

\begin{abstract}
Although sociology education is celebrating its $100^{\text {th }}$ year anniversary in Turkish higher education, the field itself is not known quite well by the society. Familial worries in the context of emotional sociology are very important because families may have when they think of their child's future especially after graduation from university. Primary aim of this paper is to find out the essence and main sources of parental worries. In this paper it is assumed that status of sociology in society and its education are inseparable parts and there are mutual relationships among them. Using phenomenological approach data gathered from 25 parents are analysed. Findings revealed that insufficient employment opportunities as well as little information about sociology are the essence or main reasons of parental concerns.
\end{abstract}

Keywords Sociology, Parents, Emotions, Phenomenology, Turkey

\section{Introduction}

Sociology as discipline introduced to Turkey during Ottoman period by Ziya Gokalp who is actually politician but latter on accepted as the founder of sociology because of his sociology lectures given by him at Istanbul University in 1914. Although as a discipline it's establishment days go back a century ago it is not a well-known field in Turkey. What sociology is and what sociologists make are the frequently asked questions. Contrary to the intellectuals, status of sociology has never been high in the eye of average people. According to Kasapoglu [1,2] and Odabas [3] sociology in Turkey is still underdeveloped and insufficient because of influence of state politics and ideology, quality of education, sociological studies and organizational problems that are also under lined by Berkes [4] in the early years. The sociology as a discipline have always been the subject of criticism and faced discrimination by the state, because the state has always been feared from sociology by assuming it as a threat for existing statues.

While hegemony (transfer of Western knowledge without critics) is very high, indigenization (meeting national targets) and internationalization (meeting international targets) are very low in Turkish sociology [5]. Actually sociology education also has structural problems rather than conjuncture based because they didn't changed in last two decades $[1,6,7]$ According to the recent nationwide study carried out with 684 sociology students from 26 university showed that gap between theory and practice because of transferring western theories without any critics, lack of dialog among sociologists and unrecognition of sociology in the society are still continuing problems. When sociology students taken in consideration majority of them reported that they are under the threat of unemployment and they study such a field they are not also able to define and explain easily to the others [7].

\section{Research problem}

According to Cresswell [8], all qualitative research traditions, including the phenomenological approach, begin with a definition of the research problem. Therefore, the research problem of this study is the following: "From the perspective of the parents what is the 'essential structure' of worries?"

The purpose of this study is to research the phenomenon of parental worries by obtaining verbal descriptions and extract the essential structure from these descriptions.

\section{Justification of the research problem}

Choosing a career is a multidimensional and continuous process which includes several steps. Knowing yourself, making decisions and finally taking action are the main steps of career planning process [9]. But in the case of sociology it is not easy to follow these steps. First of all there is a big gap between the number of students applying for the university education and the number can be enrolled by the universities. Therefore students continue their university education not in the department they chose but in the department they have been accepted. Secondly there is another big gap between number of graduates and employment opportunities in Turkey. Actually, this is the case for almost all professions. According to Kara [10] currently 19.000 students have 
studied sociology, however, only 969 of them have been employed by the state since 2003 [1,2]. It should also be noted that students' first preference is to be an officer in state with job security.

As a matter of fact as declared by American Sociological Association [11] there are three basic alternatives for sociologist in the job market namely teaching, research and sociological practice. Up to the year of 2000 majority of sociology graduates were used to be employed as teachers in secondary schools of Turkey. But this implementation is changed and secondary school teachers recruitment are limited with graduates of Faculty of Educations' rather than Faculty of Letters which used to supply $90 \%$ of sociology teachers needed. Remained two alternatives are also not realistic because there is limited number of company to employ research staff as well as practitioner of sociology.

Addition to above mentioned problems there are also another aspects worthy to discuss. For example in Turkey sociology is mostly considered as a science rather than a profession. Because of this consideration sociology curriculums are full of theoretical courses adopted from international literature without connected societies real needs. Due to the lack of links between theory and practice sociology students are not well equipped or prepared for their future professional life.

\section{Importance of research}

Because family is the most important institution parents attitudes and perceptions toward sociology is worthy to study as well as students to warn related organizations to take necessary actions.

Empirical field studies of the sociologists are very limited in Turkey [7] and none of them employed specific qualitative methodologies, such as the phenomenological approach with parents. Therefore, this is the first study to understand the emotions of sociology students' parents from their perspective using a bottom-up approach.

\section{Method}

The phenomenological approach refers to an attempt to understand empirical issues from the perspective of those being studied. Contrary to narratives that report the life of single individuals, a phenomenological study tries to give the meaning of several individuals by describing what all participants have in common as they experience a phenomenon [12]. "Phenomenology serves as a rationale behind efforts to understand individuals by entering into their field of perception to see life as these individuals see it" [13].In this qualitative study, the phenomenological approach of Moustakas' [14], which is a modification of Stevick-Colaizzi's method [15], was employed via the following steps:

a. All descriptions provided by the subjects were first taped and transcribed and later read carefully to identify aspects of empathy.

b. Several quotations were selected that indicate worries to facilitate the readers' understanding.

c. "Significant statements" (horizontalization of the data) were formulated by treating each statement as equally worthy. Similar statements were eliminated.

d. These statements were grouped into "meaning units" regarding the positive and negative experiences of parents.

e. Overall, the descriptions of the meanings were formulated to reveal the "essence" of the experiences.

In this study "snow ball sampling" is applied based on principles of theoretical sampling to reach study purpose [8], Findings are based on interviews carried out with 25 parents. After obtaining their oral consent for interviewing and recording face-to face interviews are conducted by researcher and her assistants. Most of the interviews lasted approximately an hour. Recorded interviews are deciphered as soon as possible to guaranty that no important data were lost. By reading literature and bracketing former knowledge as pointed out by Husserl [16], as "epoche", validity of research tried to be ensured. Taking field notes and interviewing until reaching saturation point are also important points and taken into consideration.

It should also be noted that in this study "empirical phenomenology" of Moustakas[14] instead "hermeneutic phenomenology" of Mannen[12] is applied. It is also assumed that this version of phenomenology is more appropriate for the study purposes. Because Moustakas focuses on experiences of participants and neglects interpretations of researcher in order to facilitate detachment instead involvement by bracketing them in terms of Husserl's concept of epoche.

\section{Limitations}

Finally, among the many limitations, one of the most important is the characteristics of the sample. The results are limited to those who are interviewed. Due to the length of the paper, positive and negative significant quotations are only given and many similar statements are also dismissed.

\section{Findings}

In this section, first positive and negative extracted significant statements of parents about sociology are listed to create a phenomenological analysis of the collected data. It would not be wrong to say that there are a equal number of positive and negative statements. Positive statements are mostly refer that sociology is an important discipline while negative statements are related to their children's future in general and employment specifically (Table 1 and Table2) 
Table 1. Significant positive statements of parents with regard to sociology.

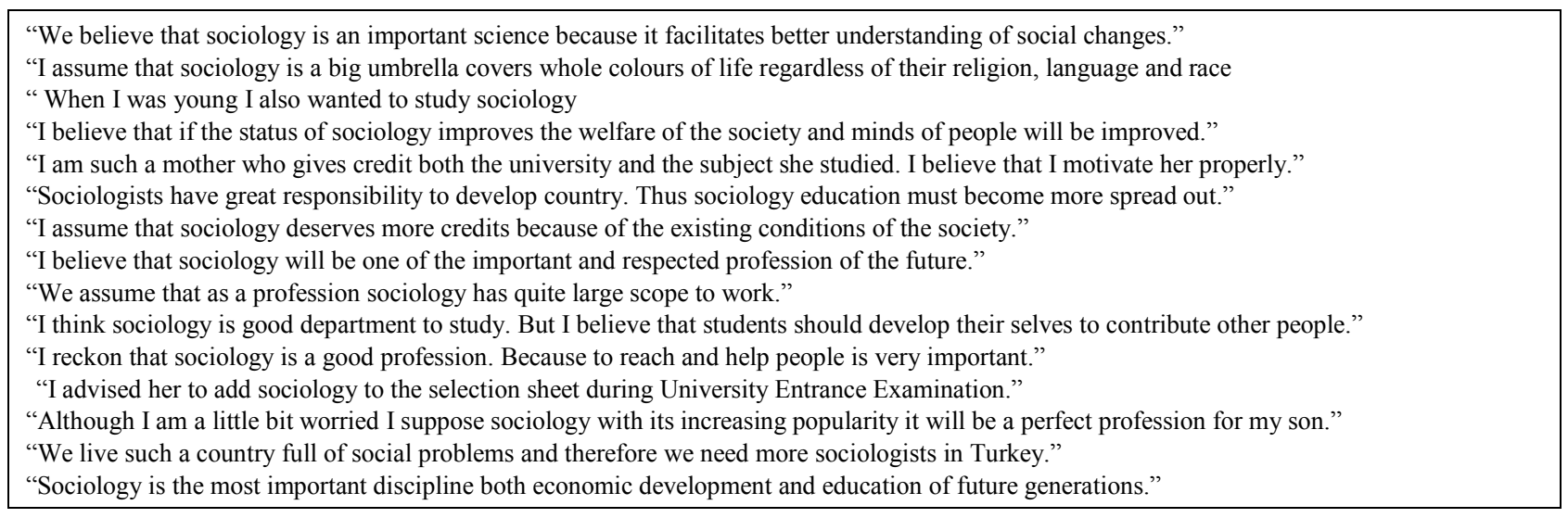

Table 2. Significant negative statements of parents with regard to sociology

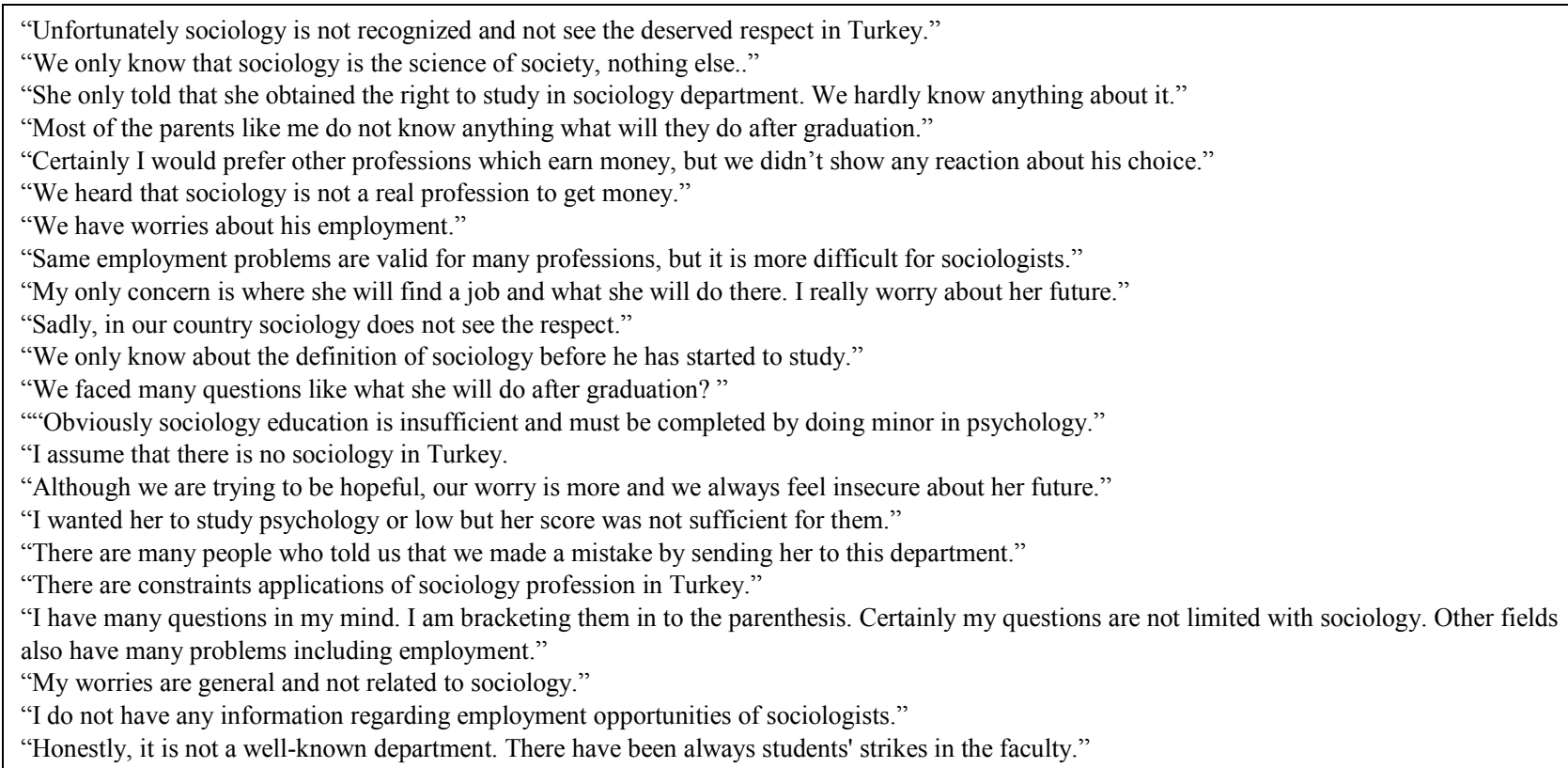

Following what sociology is, impacts of sociology education on their children are also questioned to understand parental experiences more comprehensively and these statements are given in Table 3 and Table 4. Findings show that parents' positive statements are higher than negatives.

Table 3. Parents' significant positive statements about impacts of sociology education

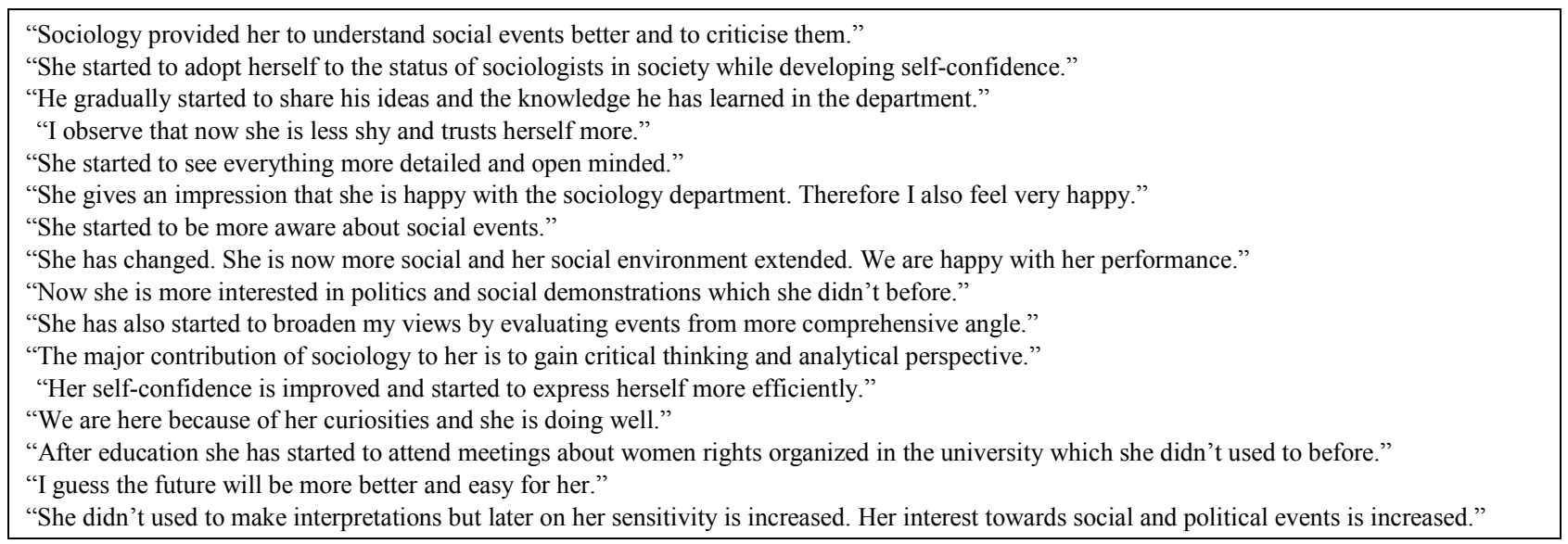


Table 4. Significant negative statements about impacts of sociology education.

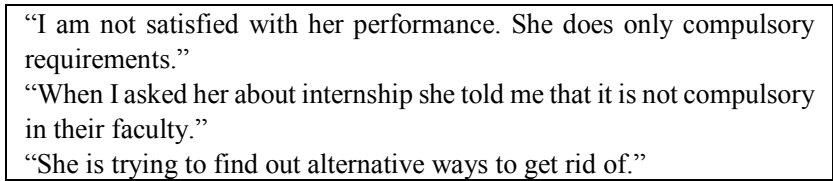

Formulated meanings of significant statements are presented in Table $5 \mathrm{a}$ and Table $5 \mathrm{~b}$ that show comparative summary of findings.

Table 5a. Formulated meanings of positive significant statements.

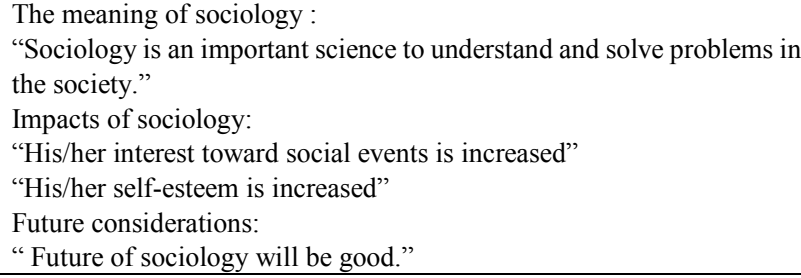

Table 5b. Formulated meanings of negative significant statements.

The meaning of sociology

"Sociology is not well recognized in Turkey."

"We didn't know much about what sociology is."

Future considerations:

"We worry about their future especially where they will work."

\section{Discussion}

Sociology of emotions is not a well-known field until Jonathan H. Turner [17] has edited a hand book with Jan E. Stets that covers many types of emotions starting from economy, work, class, health, gender, crime, sports, and extending to technology, social movements and family. According to the experts who study emotions in the family argued that" the emotional capital connects the emotions that people experience in families and experiences in other institutional arenas."[18]. When the findings of the present study are discussed by following Erickson and Cottingham [18] it will not be wrong to state that parental negative perceptions in the family are under the pressure of economy as an institution. In other words family as a core institution of the society is effected by economy or at least in close relationships with economic concerns, because majority of parents are worried about their children's future in terms of employment. On the other hand they are in dilemma because while they get reactions from their social environment and unemployment risks of their children which is $22 \%$ per year among young workers in Turkey [19] make them unhappy, they still claim that sociology is a very important field and society needs more sociologist. They also underline that impacts of sociology education on their children is positive and they are happy with these changes. If we describe their positions with a metaphor it would not be wrong to propose that parent's position is very similar to "involuntary marriage." Their emotions are in between and can be interpreted in the light of unity of opposites of dialectic logic.
Studies show that $[6,7]$ sociology students are also complain about the sociology education which is not connected to real life. In other words sociology education Turkey is mostly devoted or limited with academic sociology regardless of professional concerns. There is hardly no relationship between theoretical lessons and their application in the field. According to students, sociology curriculums should be revised and updated according to needs of job markets. They also wish a sociology without identity problem in society. Certainly there is much to do for recognition of sociology as a profession as well as academic discipline [7].

It is obvious that sociology professors and sociological associations should take necessary measures to revise their curriculums to meet demands of both discipline and graduates. Otherwise as it is revealed in this research parents will continue to be disappointed and disturbed severely. As a part of society senior sociologists or professors should be sensitive to the results of sociology education because it also effects employment of sociology graduates. As a matter of fact, studies on carrier counselling in higher education[9] should be carried in Turkey in close cooperation with career counselors and sociologist in order to find out new trends such as coaching, advising and guidance to reduce disappointments of both parents and students.

\section{Acknowledgements}

My special thanks are for all parents who voluntarily contributed and Mehmet Kilikbicen.

\section{REFERENCES}

[1] A. Kasapoglu. Yuksek Ogretimde Sosyoloji Egitiminin Sorunlar1, Ankara University: Ankara ,153 pp.1991.

[2] A. Kasapoglu. " Sociological Studies of Higher Education In Turkey", International Education Journal, 6: 537-546,2005.

[3] Y.Z. Odabas. Türkiye'de Akademik Sosyolojinin Problemleri ve Statüsü. Sosyoloji Araştırmaları Dergisi, 12:33-54,2009.

[4] N. Berkes. Sociology in Turkey. American Journal of Sociology, 42:238-24,1936.

[5] A. Kasapoglu, N. Kaya, M. Ecevit. "Centre- Periphery Relationship Between Turkish and Western Sociologies", in Facing an Unequal World Challenges (eds. M. Burawoy and M. Chang) ISA Publication 3: 97-117,2009.

[6] E.F. Kocabas, A. Hanedar. Problems of Sociology in the 100 th Anniversary in Turkey. Unpublished TUBITAK Project Report. Ankara,2013.

[7] A. Kasapoglu, B. Kavas, E. Kılıç, S. Çinar, M. Kilıkbicen. Türkiye'de Sosyoloji Eğitiminin Sorunları (Online available from www.yurtvedunyadergisi.wordpress.com). 2014.

[8] W.Creswell. Qualitative Inquiry and Research 
Design :Choosing Among Five Traditions. Sage :London, 1998.

[9] H. Pang, L. Margie, R.L. Taporek. Trends in Career Counselling in Higher Education: Voices of Career Practitioners in Australia and United States. Career Planning and Adult Development Journal,3:12-24.

[10] Z.Kara. Sosyolog Istihdami Arastirmasi, (Online available from

www.personelatama.com/2013/08/sosyologistihdami-arastir ma-raporu/)

[11] ASA. Carrier in Sociology, 2013. (www2.asanet.org/student/ career/homepage.ht)

[12] J.Van Manen. Researching Lived Experience: Human Science for an Action Sensitive Human Pedagogy. The University of Western Ontario: Ontario , 1990

[13] S.R. Bruyn. The Human Perspective in Sociology. Prentice Hall: Englewood Cliffs, N.J. 1966.
[14] C.Moustakas. (1994) Phenomenological Research Methods. Sage: Thousand Oaks CA, 1994.

[15] P. F.Colaizzi. Psychological Research as the Phenomenologist Views It. In R. Vaile and M. King (eds.), Existential Phenomenological Alternatives for Psychology (pp.48-71). Oxford University: New York, 1978.

[16] E. Husserl. Ideas: general Introduction to Pure Phenomenology (D.Carr,trans) North-western University Press: Evanston:Il.,1931.

[17] J. Stets, J.H. Turner. (eds) Handbook of the Sociology of Emotions: Volum II. Sipringer : Netherland, 2014.

[18] R.J. Erickson,, M.D. Cottingham. Family and Emotions .In Handbook of the Sociology of Emotions: Volum II.(eds. J. Stets and J.H.Turner). Springer : Netherland. pp.359-383, 2014.

[19] ILO. Youth employment in Turkey. ILO: Ankara, 2010. 